\title{
An Analysis of the Preventive Behavior and Attitudes of International Travelers from South East Asia; the Kuala Lumpur Airport Survey
}

\author{
Gerard Flaherty ${ }^{1,2 *}$, Muhammad Asyraf Maarof ${ }^{1}$, Graham Fry ${ }^{3}$ \\ 1. School of Medicine, National University of Ireland, Galway, Ireland \\ 2. International Medical University, Kuala Lumpur, Malaysia \\ 3. Tropical Medical Bureau, Dublin, Ireland
}

*Corresponding Author: Gerard Flaherty, School of Medicine, National University of Ireland, Galway, Ireland Email: gerard.flaherty@nuigalway.ie

\begin{abstract}
Introduction: There has been significant growth in international tourism from South-East Asia. Travel medicine services are still quite limited in this region. Few data exists on the knowledge, attitudes and practices of travelers from South-East Asia regarding the prevention of travel-related health risks. The present study aimed to characterize the travel trends and risk reduction strategies of international travelers departing from a major Malaysian airport.

Methods: We conducted a cross-sectional survey among international travelers at the Kuala Lumpur International Airport. A questionnaire recorded data on the demographic profile, travel patterns, travel health protective measures, sources of pre-travel health advice, personal perception of travel-related risk, and barriers to seeking health advice, travel vaccinations and malaria chemoprophylaxis.

Results: $36.8 \%$ of respondents had sought pre-travel health advice, mostly $(64.7 \%)$ from their doctor. $23.6 \%$ of the travelers had received travel vaccinations. $40 \%$ of travelers were uninsured and over $50 \%$ did not know how to access medical care overseas. The survey revealed deficiencies in the risk perception of travelers regarding endemic infectious diseases such as malaria, dengue, and rabies. A minority of the travelers reported an intention to avoid unsafe food and water, inform themselves of local disease outbreaks, pack a first-aid kit, and protect themselves from animal and mosquito bites.

Conclusions: This study highlights areas of concern in relation to the knowledge and behavior of the travelers surveyed and points to the need for raising public awareness in South-East Asia of the risks associated with international travel and the most efficient means of mitigating those risks.

Keywords: Travel Health, Vaccinations, Risk Assessment, Tropical Infection, Chemoprophylaxis, Airport Survey
\end{abstract}

Article History: Received: 2 Dec 2014; Revised: 7 Jan 2015; Accepted: 15 Jan 2015

Cite this article as: Flaherty G, Asyraf Maarof M, Fry G. An analysis of the preventive behavior and attitudes of international travelers from south East Asia; The Kuala Lumpur airport survey. Int J Travel Med Glob Health. 2015;3(1):5-9.

\section{Introduction}

Travel to and from South East Asia has witnessed a significant growth in parallel with global tourism trends in recent years. Most Asian international travelers travel within the Asian continent but tourism projections predict that the proportion of outward travelers from Asia to other continents will grow in the near future [1]. Malaysia is a rapidly developing economy which encapsulates many diverse elements of Asian culture and ethnicity, giving rise to the popular tourism slogan "Malaysia - Truly Asia". With its tropical geographical location, Malaysia is endemic for many of the infectious diseases which travel medicine professionals seek to prevent in international travelers.

Seroprevalence rates of Malaysian travelers may confer additional protection against vaccine-preventable infectious diseases, such as hepatitis A. This may serve to minimize the Malaysian traveler's perception of risk and may influence their travel health risk preventive behavior. Additionally, some travel vaccines, including hepatitis $B$, already constitute a part of the national immunisation schedule in Malaysia [2]. Specialized travel medicine clinical services are not currently well established in Malaysia. A recent editorial highlighted the need for greater research focusing on the specific needs of the Asian traveler [3]. Such evidence is essential to increase awareness of travel health preventive measures in Asian travelers and their medical professionals.

A recently published airport survey conducted at Hong Kong International Airport found a lack of preparedness amongst outbound travelers, only $10 \%$ of whom had the recommended travel vaccination coverage. An important finding was the significant proportion of higher risk travelers with pre-existing medical co-morbidities [4]. The current study was designed to investigate the travel trends and preventive attitudes of travelers departing from a major international airport in Malaysia.

\section{Methods}

The survey was conducted in Kuala Lumpur International Airport (KLIA) in May and June 2013. Research assistants invited passengers boarding for international flights to various destinations to participate in a survey. The passengers were approached at the departure gates of Kuala Lumpur International Airport (KLIA) and a self-administered, anonymous, 48-item questionnaire was distributed. 
Upon completion, the data collectors verified whether or not all questions had been answered. On average, the questionnaire was completed in 10 minutes. Only Malaysian passport holders were eligible to participate in this study. Inclusion criteria were that the subjects must be adults of 18 years of age or older with an ability to understand the language in which the questionnaires had been designed. In most cases, these criteria were determined by the data collectors upon distributing the questionnaire. The interviewers supervised the completion of each questionnaire to ensure respondents fully understood the questions.

The questionnaire included a number of personal characteristics such as age, gender, education level, profession and marital status. Questions regarding their trip included destination countries or region, purpose of trip, duration and their knowledge, attitudes and practice relating to their preferred source of travel health information, planned food ingestion habits, perceived risk of specific infectious diseases, status of travel vaccinations, perception and practice of malaria prophylaxis, vaccine-preventable and other travel-related diseases.

Results were tabulated using SPSS 20.0. All tests including descriptive analysis and comparative analysis (using t-test, Kruskal Wallis, ANOVA and chi-square tests) were interpreted at the $\mathrm{p}=.05$ significance level.

\section{Results}

In total, 498 questionnaires were returned and included in the analysis. In general, the majority of respondents were residents of Malaysia. Overall, $57 \%$ of respondents were male and $43 \%$ were female (Table 1 ). The 18 - to 25 -year age group accounted for $34.1 \%$ of responses; $31.3 \%$ of respondents were between 26 and 35 years of age, 15.9\% between 36 and 45 years of age, $12.9 \%$ between 46 and 59 years of age, and $5.8 \%$ over 60 years of age. $48.2 \%(n=240)$ of respondents were single, $50.6 \%(n=252)$ were married and $1.2 \%(n=6)$ were divorced. Regarding their educational status, more than half of the respondents $(60.8 \%, \mathrm{n}=303)$ had attained at least an undergraduate education, $14.5 \%(n=72)$ completed postgraduate studies, and the remainder had graduated from high school $(24.7 \%, \mathrm{n}=123)$. Almost half of the respondents $(46.2 \%, n=230)$ were working as professionals. Almost onethird of the respondents $(28.3 \%, n=141)$ were students, and others, including retired and unemployed individuals and housewives, comprised $16.3 \%(n=81)$ of respondents.

A great variety of reasons for traveling were reported (Table 1). $78.5 \%$ indicated leisure as their purpose for travel. Business travelers accounted for $14.9 \%$ of travelers in this study. $96 \%$ of respondents planned to remain abroad for less than 1 week, $3 \%$ for 1 to 2 weeks, $0.4 \%$ for 3 to 4 weeks, and $0.6 \%$ for more than 4 weeks.

South East Asia was the most common region visited (47.6\%), followed in descending order by the Middle East (17.3\%), East Asia (15.9\%), Europe (10\%), Australia (6.8\%), the Americas and other regions including Africa, India and
Russia (1.2\%). In terms of the average number of international trips taken every year, the respondents reportedly took 2 international trips each year with a minimum of 1 trip and a maximum of 10 trips reported per year. The majority of the respondents $(78.3 \%)$ were traveling to a single country whereas $21.7 \%$ traveled to multiple countries. Four out of every five respondents were staying at a hotel during the trip, followed by residential (11.3\%), and hostel (4.8\%) settings. The oldest respondents tended to prefer to travel to the Americas with a median age of 40, followed by Europe (median age 34), Middle East (median age 33.5), South East Asia (median age 29), East Asia (median age 28), and Australia (median age 22.5).

$69.2 \%$ of the travelers felt informed of local disease outbreaks whereas $17 \%$ of them were unlikely to inform themselves about local disease outbreaks. More than half of the respondents (53.4\%) did not familiarize themselves with procedures to access medical care in the event of illness during travel. $81 \%$ of the interviewed travelers planned to consistently restrict their consumption of all "potentially unsafe food items" listed (for example, ice cream, ice cubes in drinks, tap water, unpeeled or uncooked fruit, salads, and shellfish).

Table 1. Demographic and travel characteristics of travelers departing from Kuala Lumpur International Airport

\begin{tabular}{|c|c|c|}
\hline & Frequency (n) & $\%$ \\
\hline \multicolumn{3}{|c|}{ Gender } \\
\hline Male & 284 & 57 \\
\hline Female & 214 & 43 \\
\hline \multicolumn{3}{|c|}{ Age group } \\
\hline $18-25$ years & 170 & 34.1 \\
\hline $26-35$ years & 156 & 31.3 \\
\hline $36-45$ years & 79 & 15.9 \\
\hline $46-59$ years & 64 & 12.9 \\
\hline$>60$ years & 29 & 5.8 \\
\hline \multicolumn{3}{|c|}{ Marital status } \\
\hline Single & 240 & 48.2 \\
\hline Married & 252 & 50.6 \\
\hline Divorced & 6 & 1.2 \\
\hline \multicolumn{3}{|c|}{ Level of education } \\
\hline High school & 123 & 24.7 \\
\hline Undergraduate & 303 & 60.8 \\
\hline Postgraduate & 72 & 14.5 \\
\hline \multicolumn{3}{|c|}{ Occupation } \\
\hline Professional & 230 & 46.2 \\
\hline Non-professional & 46 & 9.2 \\
\hline Student & 141 & 28.3 \\
\hline $\begin{array}{l}\text { Retired/Unem- } \\
\text { ployed/Housewife }\end{array}$ & 81 & 16.3 \\
\hline \multicolumn{3}{|c|}{ Travel frequency } \\
\hline Once per year & 210 & 42.5 \\
\hline 2 to 3 times per year & 208 & 42.1 \\
\hline 4 or more times per year & 76 & 15.4 \\
\hline \multicolumn{3}{|c|}{ Purpose of travel } \\
\hline Leisure & 346 & 69.5 \\
\hline Business & 30 & 6.0 \\
\hline Both & 122 & 24.5 \\
\hline \multicolumn{3}{|c|}{ Pre-travel health advice obtained } \\
\hline Yes & 183 & 36.8 \\
\hline No & 314 & 63.2 \\
\hline
\end{tabular}


$10.4 \%$ stated they would not apply any dietary restrictions. The remainder $(8.8 \%)$ claimed that they would avoid some of the items on some occasions. Those who traveled for the purposes of visiting their relatives and for leisure purposes were more unlikely to avoid unsafe food and water than business travelers.

Approximately $45 \%$ of travelers surveyed, considered vaccinations essential and were willing to pay to receive them. At least $27.8 \%$ had one negative opinion regarding vaccination and were not willing to pay for vaccinations. In the intended malaria or dengue endemic destinations, $62.8 \%$ of the travelers planned personal protection measures against mosquito bites, such as using insect repellents and wearing long clothes. Approximately $43 \%$ of travelers did not have medical insurance or were unsure as to whether or not their insurance policy would cover their medical expenses during the period of travel. Up to $61 \%$ were likely to buy travel health insurance if their travel budget allowed this expenditure.

In terms of pre-travel health advice, nearly two-thirds of the respondents (63.2\%) had not sought travel health advice prior to the trip. Among the one-third who did seek travel health advice, $67.6 \%$ had consulted their general practitioner, $11.8 \%$ searched the internet for information, $9.4 \%$ obtained advice from family and friends, and $6.5 \%$ did so from travel agents. Health advice received from healthcare professionals
Table 2. Reported barriers to seeking pre-travel health advice

\begin{tabular}{lcc}
\hline $\begin{array}{l}\text { Perceived Barriers to Seeking Travel } \\
\text { Health Advice }\end{array}$ & Frequency (n) & \% \\
\hline Concerned about potential side effects & 109 & 21.9 \\
Do not consider themselves at risk & 104 & 20.9 \\
Financial constraints & 66 & 13.3 \\
Fear of needles & 57 & 11.4 \\
Not a priority & 43 & 8.6 \\
$\begin{array}{l}\text { Unsure of where to access infor- } \\
\text { mation }\end{array}$ & 37 & 7.4 \\
Immune to tropical disease & 29 & 5.8 \\
No specialized service offered locally & 28 & 5.6 \\
$\begin{array}{l}\text { Unsure about the effectiveness of ad- } \\
\text { vice and vaccinations }\end{array}$ & 25 & 5.0 \\
\hline
\end{tabular}

was perceived to be more reliable than from other sources. With respect to pre-travel health advice barriers, few were identified which would have prevented the respondents from seeking it (Table 2). 22\% $(n=109)$ of the respondents were concerned about the potential side effects of vaccines, and $21 \%(n=104)$ did not consider themselves to be at risk of acquiring any illness during their travels. Financial constraints and fear of needles were also identified as a barrier with $13.3 \%(n=66)$ and $11.4 \%(n=57)$, respectively, of respondents citing this barrier. $5.8 \%(n=29)$ claimed that they were already immune to tropical diseases, whereas $5.6 \% \quad(n=28)$ claimed that there was no specialized travel medicine service offered locally.

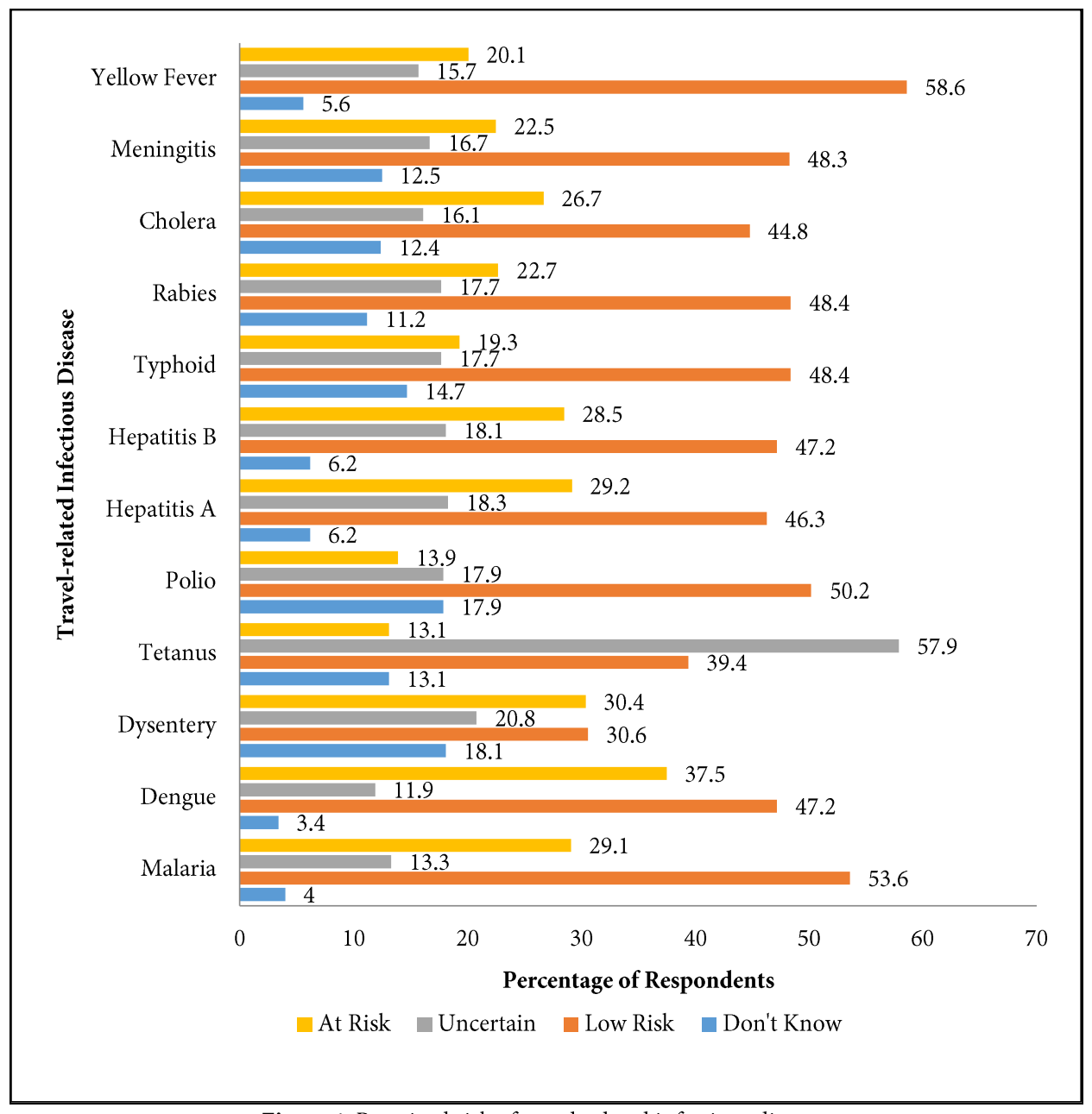

Figure 1. Perceived risk of travel-related infectious diseases 
All participants were asked to estimate the risk for a number of travel-related infectious diseases, from the point of view of a general traveler visiting their proposed destination. Unfamiliarity was highest for dysentery, polio, cholera and typhoid fever, somewhat lower for hepatitis A and B and malaria, and lowest for dengue fever. Travelers rated their personal risk of acquiring dengue infection the highest amongst the infectious diseases presented to them. Nevertheless, this risk was considered to be high by only $38 \%$, and to be low by a further $47.2 \%$. The average scores for other typical travelrelated infectious diseases endemic in some destinations visited, such as yellow fever, rabies, tetanus and meningitis varied from $20 \%$ to $29 \%$ for the "at risk" category. Those who were traveling for leisure purposes (39\%) assumed that they were protected against hepatitis A to a greater extent than business travelers (5.4\%). In the case of hepatitis B, $47.2 \%$ considered that they were protected, $18.1 \%$ thought that they might be protected, and $28.5 \%$ believed that they had no protection against the disease.

\section{Discussion}

This cross-sectional airport survey provides valuable insights into the knowledge, attitudes and behaviors of a sample of Malaysian travelers departing from a major international airport, mostly to other Asian countries. In keeping with the demographic profile of the country itself, nearly two-thirds of travelers surveyed were younger than 35 years of age and three-quarters were educated to third level or greater. Leisure travel dominated this airport survey and the vast majority of trips were of short duration. As disposable income increases throughout Asia, it is likely that travel duration will witness a corresponding increase, with its attendant heightened travel health risks. Of interest is the finding that over a fifth of travelers planned to visit multiple countries during their relatively short trips. This is in keeping with tourist trends observed elsewhere and is an important factor in determining the magnitude of travel health risk. Younger travelers in this study were observed to be more likely to travel within Australasia while older travelers ventured further afield, with trips to North and South America and Europe.

This study exposes deficiencies in travelers' preparedness for healthy travel, with $43 \%$ of participants traveling without travel health insurance and an alarming $63.2 \%$ of travelers failing to obtain pre-travel health advice for their current trip. This proportion is consistent with the low rates observed in other airport surveys [5-9]. In a survey carried out at John F. Kennedy International Airport in New York, only $36 \%$ of departing travelers had sought travel health advice prior to travel [10]. In airport surveys conducted at Sydney and Bangkok airports, Asian travelers were found to be less likely to seek pre-travel health advice and accept travel vaccines than Australian or other Western travelers [7]. In a multivariate analysis of data collected at Boston Logan International Airport, certain factors predicted a higher likelihood of not seeking travel health information among travelers to low-or low-middle income countries. These included solo travel, travel for less than 2 weeks, and vacation travel [11]. Of those travelers who had sought travel health counseling, over a quarter of them had received this from a source other than a healthcare professional. Internet sources were rated less highly in this survey than in a health survey of travelers conducted in Peru [12], but with the growing internet connectivity in South-east Asia it is reasonable to suggest that this will become a more important primary source of travel health-related information in the future.

This study highlights some of the traveler-perceived barriers to seeking pre-travel health advice and preventive measures, with vaccine side effects and a low perception of risk being prominent factors among these travelers. Vaccine acceptability levels reported in this study compare well with those published in an airport survey at Munich International Airport [13]. Over half of the travelers in our study admitted that they were unsure about how to access competent medical care were they to become ill during their journeys abroad. While the majority of travelers declared that they would avoid unsafe food and water while traveling, over a third did not intend to use mosquito bite avoidance strategies such as the application of insect repellent. Previous airport surveys in Europe have demonstrated a differential level of awareness of malaria amongst travelers, with an increase in self-protection rates with travel to high-risk destinations for malaria [14]. Almost a quarter of the travelers visiting a high-risk malaria area in a large European cohort reported an erroneous risk perception [6], a finding reinforced by the present study. While this study did not correlate specific destinations with travelers' reported knowledge, attitude and practices, it did reveal a general lack of awareness of the risk of acquiring several common travel-related infectious diseases, including dysentery and typhoid fever. Despite a greater level of risk awareness in relation to dengue infection which is endemic in Malaysia, nearly half of the travelers in the study considered themselves to be at low risk of contracting dengue virus. There was a particularly low level of risk awareness towards hepatitis A and B infection but seroprotection from natural immunity (hepatitis A) or childhood immunization (hepatitis B) may have influenced this perception in this cohort of Malaysian travelers. Since seroprevalence rates for hepatitis A infection are likely to decrease over time [15], it is important to give priority for protecting travelers against this common vaccine-preventable travel-related disease [16]. In the Dutch Schiphol airport survey, preventive behavior of European travelers to destinations at risk for hepatitis A increased over a 7 year period, an improvement attributed to the effectiveness of travel health advice [17].

This study has yielded useful insights into the knowledge, attitudes and practices of Malaysian travelers. Further studies with a larger sample size should be conducted at other regional airports at various times of the year in an effort to further characterize the typical profile of international travelers departing from Asian countries, including those with pre-existing medical conditions. These data will help to inform the development of specialized travel health services and will help to shape postgraduate educational programmes which will serve the needs of travelers and their healthcare providers.

\section{Conclusion}

This study highlights deficiencies in the knowledge, attitudes and preventive behavior of international Malaysian travelers and raises the need for public awareness campaigns in South East Asia aimed at educating the traveling public about the health risks associated with international travel and the most efficient means of mitigating those risks. The development of 
specialist travel medicine services throughout Malaysia and other Asian countries should be informed by these important traveler-related factors.

\section{Acknowledgements}

The authors wish to thank Andrew Lewis from Tropical Medical Bureau for his support, Mrs. Eli Ilyana from Malaysia Airports Holdings for granting permission to conduct the survey in Kuala Lumpur International Airport, and the following research assistants: Alif Haziq Rahim, Amirah Syafawani, Hazmi Shah, and Adam Byrne.

\section{Authors' Contribution}

The authors were involved in the study design, data collection, interpretation of the results, and preparation of the manuscript.

\section{Funding/Support}

This study was supported by an unrestricted educational grant received from Enterprise Ireland.

\section{Financial Disclosure}

The authors state that they have no Financial Disclosure.

\section{References}

1. United Nations World Tourism Organization (UNWTO). Tourism towards 20130. Available from http://www.world-tourism.org [Cited 24 December 2014].

2. World Health Organization. WHO Vaccine Preventable Diseases Monitoring System 2012. Available from http://apps.who.int/immunization_monitoring/en/globalsummary/countryprofileselect.cfm [Cited 24 December 2014].

3. Travel medicine for Asian travelers - do we need new approaches? J Travel Med. 2012;19(6):335-7.
4. Hung KKC, Lin AKY, Cheng CKY, Chan EYY, Graham CA. Travel health risk perceptions and preparations among travelers at Hong Kong International Airport. J Travel Med. 2014;21(4):288-91.

5. Van Herck K, Zuckerman J, Castelli F, Van Damme P, Walker E, Steffen R. Travelers' Knowledge, attitudes, and practices on prevention of infectious diseases: results from a pilot study. J Travel Med. 2003;10:75-8.

6. Van Herck K, Castelli F, Zuckerman J, Nothdurft H, Van Damme P, Dahlgren AL, et al. Knowledge, attitudes and practices in travel-related infectious diseases: The European Airport Survey. J Travel Med. 2004;11:3-8.

7. Heywood AE, Watkins RE, Iamsirithaworn S, Nilvarangkul K, Maclntyre CR. A cross-sectional study of pre-travel health-seeking practices among travelers departing Sydney and Bangkok airports. BMC Public Health. 2012;12:321-9.

8. Lopez-Velez R, Bayas JM. Spanish travelers to high-risk areas in the tropics: airport survey of travel health knowledge, attitudes, and practices in vaccination and malaria prevention. $J$ Travel Med. 2007;14(5):297-305.

9. Wilder-Smith A, Khairullah NS, Song JH, Chen CY, Torresi J. Travel health knowledge, attitudes and practices among Australasian travelers. J Travel Med. 2004;11:9-15.

10. Hamer DH, Connor BA. Travel health knowledge, attitudes and practices among United States travelers. J Travel Med. 2004;11:23-6.

11. LaRocque RC, Rao SR, Tsibris A, Lawton T, Barry MA, Marano N, et al. Pre-travel health advice-seeking behavior among US international travelers departing from Boston Logan International Airport. J Travel Med. 2010;17(6):387-91.

12. Cabada MM, Maldonado F, Quispe W, Serrano E, Mozo Karen, Gonzales E, et al. Pretravel health advice among international travelers visiting Cuzco, Peru. J Travel Med. 2005;12:61-5.

13. Schunk M, Wachinger W, Nothdurft HD. Vaccination status and prophylactic measures of travelers from Germany to subtropical and tropical areas: results of an airport survey. J Travel Med. 2001;8:2602.

14. Van Genderen PJJ, Van Thiel PPAM, Mulder PGH, Overbosch D Trends in the knowledge, attitudes and practices of travel risk groups towards prevention of malaria: results from the Dutch Schiphol Airport Survey 2002 to 2009. Malaria J. 2012;11:179-88.

15. Jacobsen KH, Koopman JS. Declining hepatitis A seroprevalence: a global view and analysis. Epidemiol Infect. 2004;132:1005-22.

16. Askling HH, Rombo L, Andersson Y, Martin S, Ekdahl K. Hepatitis A risk in travelers. J Travel Med. 2009;16:233-8.

17. Van Genderen PJJ, Van Thiel PPAM, Mulder PGH, Overbosch D. Trends in the knowledge, attitudes and practices of travel risk groups towards prevention of Hepatitis A: results from the Dutch Schiphol Airport Survey 2002 to 2009. J Travel Med. 2012;19(1):35-43. 